\title{
Clinical Aspects and Management of Children in Otorhinolaryngological Consultation: Case of University Clinics of Lubumbashi (DR Congo)
}

\author{
Yowa Muya Sandra ${ }^{*}$, Kanteng Gray ${ }^{2}$, Nyembo Luty Albert' ${ }^{1}$ Mutombo Mulangu Augustin², \\ Luboya Numbi Oscar ${ }^{2}$
}

${ }^{1}$ Department of Otorhinolaryngology, University Clinics of Lubumbashi, University of Lubumbashi, Lubumbashi, The Democratic Republic of the Congo

${ }^{2}$ Department of Paediatrics, Lubumbashi University Clinics, University of Lubumbashi, Lubumbashi, The Democratic Republic of the Congo

Email: *sandrasym17@gmail.com

How to cite this paper: Sandra, Y.M., Gray, K., Albert, N.L., Augustin, M.M. and Oscar, L.N. (2019) Clinical Aspects and Management of Children in Otorhinolaryngological Consultation: Case of University Clinics of Lubumbashi (DR Congo). Open Access Library Journal, 6: e5729.

https://doi.org/10.4236/oalib.1105729

Received: August 23, 2019

Accepted: September 16, 2019

Published: September 19, 2019

Copyright $\odot 2019$ by author(s) and Open Access Library Inc.

This work is licensed under the Creative Commons Attribution International License (CC BY 4.0).

http://creativecommons.org/licenses/by/4.0/

(c) $\underset{\mathrm{EY}}{\mathrm{B}}$ Open Access

\begin{abstract}
Introduction: Otorhinolaryngological pathologies in children are a problem in sub-Saharan Africa because they are frequent and complex, yet poorly described, and their management poses a real challenge. The objective of this study was to describe the clinical and therapeutic characteristics, as well as to establish a diagnostic and topographic grouping of the main ENT diseases in children attending the ENT department of the University Clinics of Lubumbashi (DR Congo). Methods: A cross-sectional and retrospective study was conducted over a period of 2 years, from January 2014 to December 2015, 309 cases of children under 19 years of age were recorded. Results: An overall consultation frequency of $19.05 \%$ was noted. The mean age was $7.08 \pm 5.37$ years and $48.8 \%$ of cases were less than 5 years old. $1.9 \%$ of cases were referred; $58.3 \%$ of cases received initial self-medication before consulting. In the hospital, antibiotic treatment was prescribed in $67.2 \%$ of cases, anti-inflammatory in $62.8 \%$ of cases and surgery was necessary for $2 \%$ of cases. Otitis was the most common (37.7\%), followed by tonsillitis (20.7\%) and cerumen impaction (20.7\%). Otologic complaints dominated with $67.7 \%$; Otalgia and otorrhea were the most common complaints. In the field of rhinology, rhinorrhea and nasal encryption were predominant, while odynophagia and cough dominated complaints in laryngopharyngology and appendices. Conclusion: ENT pathologies in children are frequent and dominated by infectious pathology. Their management is often simple and their evolution generally favorable.
\end{abstract}

\section{Subject Areas}

Otorhinolaryngology, Pediatrics 


\section{Keywords}

Otorhinolaryngology, Consultations, Children, DR Congo

\section{Introduction}

Otorhinolaryngological diseases or Ear, Nose and throat diseases (ENT) in sub-Saharan Africa are rich and varied. A study conducted in Guinea Conakry reported an incidence of ENTs about $8.14 \%$ in all multidisciplinary consultations [1]. Some studies concerning these conditions have demonstrated an incidence of $41 \%$ in children under 15 years in Nigeria [2] and 20\% of ENT emergencies in patients under 15 years in Douala, Cameroon [3]. Other studies have reported a high frequency of these pathologies in children, $52.72 \%$ of children received urgently in the ENT-CFS department of Yopougon University Hospital in Ivory Coast [4] and 11.23\% in Antananarivo in Madagascar [5]. Otherwise, pediatric ENT consultations accounted for $26.8 \%$ of all ENT-CFS consultations at Duke University Medical Center in North Carolina in the United States [6], and 21\% of children under 10 years old. 15 years were received in outpatient ENT consultation at the Clinical Hospital of the University of Chile, Chile [7]. This shows that pediatric ENT consultations represent a significant proportion of registered cases, and deserve special attention.

Despite the importance of these pathologies, few studies have been conducted concerning the clinical aspects and management of children in ENT consultation and particularly in a context of under-equipment and difficult accessibility to health care. Our study focused specifically on children considering their vulnerability to certain life-threatening ENT conditions due to their complications. This study is aiming to describe the clinical and therapeutic characteristics, to establish a diagnostic and topographic grouping of the main ENT diseases in children attending the ENT department of Lubumbashi University Clinics.

\section{Methods}

\subsection{Study Environment}

The present study was conducted at University Clinics in Lubumbashi; located in the city of Lubumbashi; in DR Congo. Lubumbashi is the second largest city in DR Congo, with a population around 2 million according to the latest estimates [8]. This city is organized into 7 municipalities; one of which, peripheral is urban-rural type. Lubumbashi University Clinics is a tertiary level hospital; highest level according to the health care system in DR Congo. Specialized consultations are organized in various fields, including ENT. The ENT department organizes outpatient consultations at the dispensary, and the patients requiring hospitalization are in the services of Surgery or Pediatrics according to their age. The service includes the expertise of at least one ENT specialist and general practitioners. 


\subsection{Type and Duration}

This is a cross-sectional and retrospective descriptive study conducted over a period of 2 years from January 2014 to December 2015.

\subsection{Size and Type of Sample}

We performed a convenience sampling, based on the inclusion criteria described below. A total of 309 cases were collected for this study.

\subsection{Inclusion Criteria}

Were included in this study, children aged less than 19 years of age during the study period, who have been seen in the ENT service, and for whom a diagnosis was documented and treatment was undertaken.

\subsection{Criteria for Non-Inclusion}

The adults and patients for whom clinical data were not available were excluded from the study.

\subsection{Data Collection}

We carried out a documentary review of the cases recorded in the registers and medical form.

\subsection{Parameters}

The following parameters were collected: age, sex, origin, admission complaints, initial treatment, diagnosis, treatment regimen used and outcome of treatment.

\subsection{Statistical Analyzes}

The data has been encoded and analyzed with Epi-info 7, on Windows. Thus, the frequencies were generated, with their means and standard deviation.

\section{Results}

There were 309 cases of children 18 years or younger out of 1622 ENT consultations in general, a frequency of $19.05 \%$.

Table 1 shows that the average age is $7.08 \pm 5.37$ years. Almost half of the cases are in the age group of children under 5 years old. The sex ratio is 1.45 for girls; and most of the children come from Lubumbashi commune.

Table 2 shows that less than $2 \%$ of cases were referred; $58.3 \%$ of cases received initial self-medication before consulting. In the hospital, antibiotic treatment was prescribed in $67.2 \%$ of cases and anti-inflammatory drugs in $62.8 \%$ of cases and surgery was necessary for only $2 \%$ of cases. Otitis was the most common (37.7\%), followed by tonsillitis (20.7\%) and cerumen cap (20.7\%). The majority of patients were treated as outpatients (98.7\%); no deaths were recorded.

Figure 1 shows that otology dominated complaints with $67.7 \%$ and $6.8 \%$ of cases presented complaints related to the three subspecialties. 
Figures 2-4 show that in otology, otalgia and otorrhea are the most common complaints. In rhinology, however, rhinorrhea and nasal encryption are predominant. In laryngo-pharyngology and appendices, odynophagia and coughing come first.

Table 1. Distribution of cases according to the socio-demographic parameters.

\begin{tabular}{|c|c|c|c|c|}
\hline \multicolumn{2}{|c|}{ Parameters } & \multirow{2}{*}{$\begin{array}{c}\text { Effectif } \\
73\end{array}$} & \multirow{2}{*}{$\begin{array}{c}\text { Percent } \\
23.6\end{array}$} & \multirow[t]{2}{*}{ Other parameters } \\
\hline & $\leq 2$ & & & \\
\hline & $3-5$ & 78 & 25.2 & \\
\hline \multirow[t]{4}{*}{ Age (years) } & $6-12$ & 87 & 28.2 & $\begin{array}{c}\text { Mean }=7.08 \pm 5.37 \\
\text { years }\end{array}$ \\
\hline & $\geq 13$ & 71 & 23 & \\
\hline & Total & 309 & 100 & \\
\hline & Male & 144 & 46.6 & \\
\hline \multirow[t]{6}{*}{ Sex } & Female & 165 & 53.4 & Sex-ratio $\mathrm{F} / \mathrm{M}=1.45$ \\
\hline & Total & 309 & 100 & \\
\hline & Lubumbashi & 154 & 49.8 & \\
\hline & Kampemba & 73 & 23.6 & \\
\hline & Kamalondo & 6 & 1.9 & \\
\hline & Katuba & 13 & 4.2 & \\
\hline \multirow[t]{5}{*}{ Origin } & Kenya & 4 & 1.3 & \\
\hline & Annexe & 37 & 12.0 & \\
\hline & Ruashi & 16 & 5.2 & \\
\hline & Out of town & 6 & 1.9 & \\
\hline & Total & 309 & 100 & \\
\hline
\end{tabular}

Table 2. Case distribution according to the clinical and therapeutic aspects.

\begin{tabular}{|c|c|c|c|}
\hline \multicolumn{2}{|c|}{ Parameters } & \multirow{2}{*}{$\begin{array}{c}\text { Effectif } \\
303\end{array}$} & \multirow{2}{*}{$\begin{array}{c}\text { Percent } \\
98.1\end{array}$} \\
\hline \multirow{3}{*}{ Consultation status } & Spontaneous & & \\
\hline & Refered & 6 & 1.9 \\
\hline & Total & 309 & 100 \\
\hline \multirow{3}{*}{ Initial self medication } & Yes & 180 & 58.3 \\
\hline & No & 129 & 41.7 \\
\hline & Total & 309 & 100 \\
\hline \multirow{6}{*}{ Type of treatment } & Antibiotherapy & 205 & 67.2 \\
\hline & Antiinflammatory & 194 & 62.8 \\
\hline & Mouthwashes & 33 & 10.7 \\
\hline & Otic drops & 163 & 52.7 \\
\hline & Nasal spray or drops & 131 & 42.4 \\
\hline & Surgery & 6 & 1.9 \\
\hline
\end{tabular}




\section{Continued}

\begin{tabular}{cccc}
\hline & Other acts & 91 & 29.4 \\
\hline & Otitis & 117 & 37.7 \\
& Cerumen cap & 62 & 20.0 \\
& Tonsilitis & 64 & 20.7 \\
Diagnosis retained & Pharyngitis et rhino-pharyngitis & 60 & 19.4 \\
& Rhinitis & 47 & 15.2 \\
& Rhino-sinusitis & 15 & 4.8 \\
& Foreign body & 18 & 5.8 \\
& Others & 30 & 9.7 \\
\hline \multirow{2}{*}{ Traitement mode } & Ambulatory & 305 & 98.7 \\
& Hospitalisation & 4 & 1.3 \\
\hline \multirow{2}{*}{ Evolution } & Healling & 137 & 44.3 \\
& Death & 0 & 0.0 \\
& Lost of view & 172 & 55.7 \\
\hline
\end{tabular}

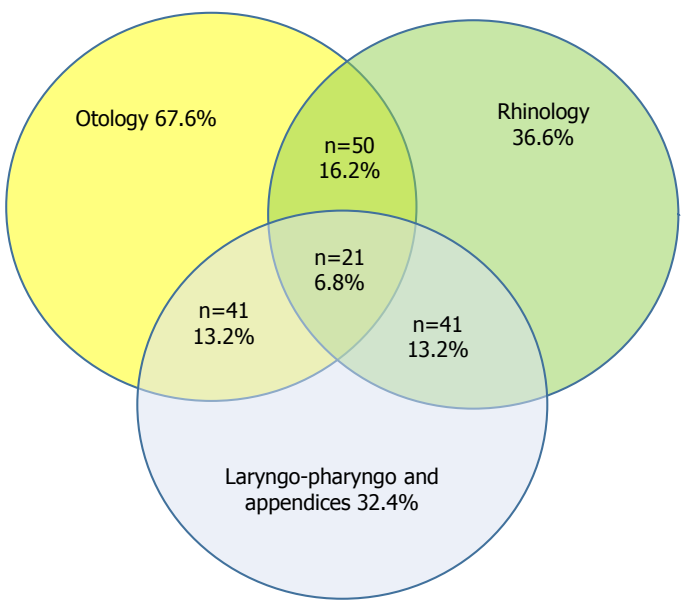

Figure 1. Case distribution according to the complaint field.

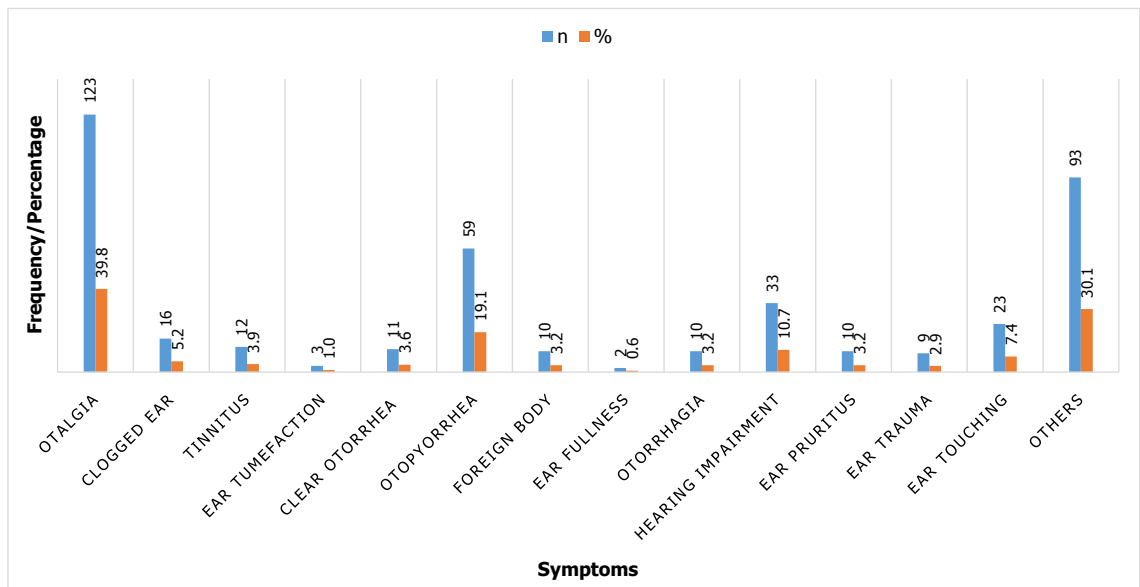

Figure 2. Distribution of otology symptoms. 


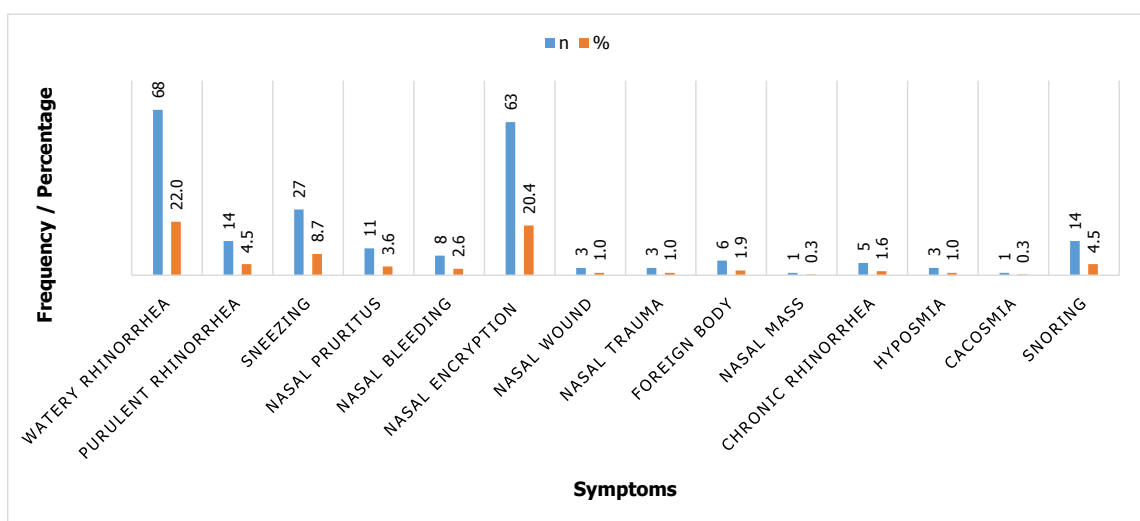

Figure 3. Distribution of rhinology symptoms.

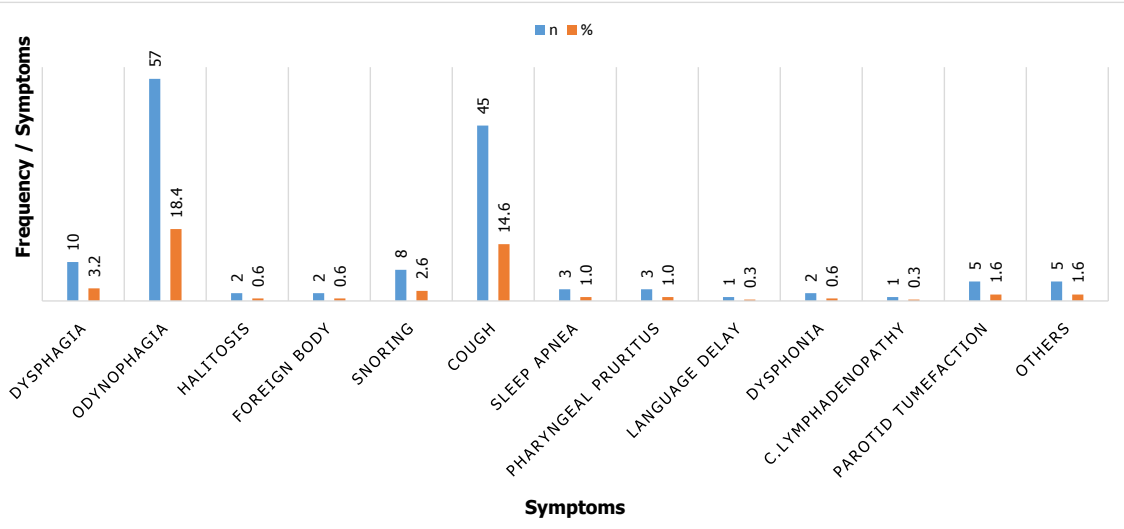

Figure 4. Distribution of laryngology, pharyngology and appendices symptoms.

\section{Discussion}

\subsection{Frequency and Socio-Demographic Aspects}

Our study shows a frequency of $19.4 \%$ of cases of pediatric consultations. This figure coincides with that of Donkeng in Cameroon [3], for whom children accounted for $19.4 \%$ of cases in all ENT emergencies and close to that of Seymour in Chile [7] with $21 \%$ of children under 15 years old received in an outpatient ENT consultation. Other authors have found a high frequency of outpatient consultations or ENT emergencies, $41 \%$ for Fasunla in Nigeria [2]; $52.72 \%$ for Badou-N'Guessan in Ivory coast [4]; 11.23\% for Ramarozatovo in Madagascar [5]; 26.8\% for Choi in the United States [6]. The frequency of pediatric ENT consultations could have been higher if some cases were not directly treated in the pediatric ward of the same hospital.

It should be noted that there are three declared ENT services on the city, including the University Clinics of Lubumbashi. Yet, in common practice, most cases are treated by physicians with generalist skills. Hence the importance of an efficient care system that promotes information, sorting and referral of patients to more appropriate and certainly more specific care.

We noted in our series a female predominance with a sex ratio of 1.45 . This 
was also the case for Seymour in Chile [7] Attifi in Guinea-Conakry [1] for all ENT consultations at all ages. Other authors have found a predominance of the male sex [2] [3] [4] [5] [6] [9] [10] [11]. Sereme in Burkina-Faso [12] found a sex ratio of 1 . There is no particular reason for mentioning these differences.

In our series, the average age is $7.08 \pm 5.37$ years. Almost half of the cases are in the age group of children under 5 (48.8\%). These findings are similar to those of other authors [4] [5] [11] Indeed, infections of the ENT sphere are common in children for morphological and functional reasons making them more vulnerable than adults [13].

In relation to the origin of the patients, $49.8 \%$ of the cases came from the commune of Lubumbashi. It is one of the most populated municipalities of the city and the geographical situation of the University Clinics in this municipality would explain a better accessibility.

\subsection{Clinical Aspects}

Most of the patients, $98.06 \%$, had come for spontaneous consultation while only $1.94 \%$ had been referred. This underlines the importance of improving interdisciplinarity on the one hand, but also increasing medical staff's awareness of the orientation of ENT cases towards the most appropriate service.

In our series, otology accounted for $67.6 \%$ of complaints followed by rhinology and laryngo-pharyngology and appendices (neck and salivary glands) with respectively $36.6 \%$ and 32.4\%. Furtado in Brazil [14] also found a prevalence of otological complaints. This frequency distribution was also found in the study by José Santos De Andrade in Brazil [15] with a predominance of otology cases in all ENT emergencies of his series as well as a high frequency of ear infections. Pharyngo-esophageal emergencies were more common in the Adedeji series in Nigeria [10]. This distribution, in our series, would be due to the fact that the parents take spontaneously their children whose ears are painful or sink in the service of ENT whereas that is not generally the case for the complaints concerning the rest of the sphere ENT for which they consult most often the pediatrician or a general practitioner in the first place.

The most common complaint was earache with $39.8 \%$ of cases in otology. This is probably due to the fact that pain is one of the symptoms difficult to bear especially for children. In rhinology, clear rhinorrhea was the most common symptom with $22.0 \%$ of cases. Discomfort caused by this symptom; the desire to see it disappear as soon as possible, the fear of the occurrence of rhinosinusic complications could explain the high frequency of consultations for this complaint. Odynophagia accounted for $18.4 \%$ of the laryngology and pharyngology cases associated with the appendices. This could have an explanation similar to that of earache.

For diagnosis, the most common in our series was ear infections in $37.86 \%$ of cases. Fasunla in Nigeria [2], José Santos Cruz de Andrade in Brazil [15], Sahin in Turkey [16] and Kishve in India [17] also found a predominance of ear infec- 
tions. Adhikari in Nepal [18] found in his study that otitis came in second place after cerumen cap. For Lalwani [19] acute otitis media is the most common infectious pathology of children with a peak frequency during the first two years of life.

In sub-specialties, otitis accounted for $37.86 \%$ of otology cases; tonsillitis $20.71 \%$ of cases in pahyno-laryngology associated with appendages and rhinitis $15.21 \%$ of cases of rhinology. Kishve in India [17] found the same distribution of the most frequent diagnoses related to sub-specialties, $31.8 \%$ otitis in otology; $38.2 \%$ rhinitis in rhinology and $42.9 \%$ tonsillitis in laryngo-pharyngology. These high figures of infectious diseases could be explained by the poor hygiene of life, self-medication, tropical climatic conditions and the high level of pollution of the city of Lubumbashi.

\subsection{Therapeutic and Evolutionary Aspects}

Initial treatment was initiated by self-medication or prescription in $58.25 \%$ of cases. This is explained in our series by the fact that parents tend to give drugs to their children without prior medical advice or to seek advice from the pharmacist who often recommends symptomatic treatment regardless of the cause. Some use a relative who is in the medical field (doctor or nurse) who advises a product without having examined the patient.

Regarding the type of treatment after ENT consultation, antibiotic therapy was instituted in $67.21 \%$ of cases; an anti-inflammatory given in $62.78 \%$ of cases. Only $1.94 \%$ of cases had surgery. The medical treatment is based on an initially probabilistic antibiotherapy instituted as soon as the patient is admitted and secondarily adapted to the results of the antibiogram [12]. This high proportion of antibiotic treatment in our series, while most children's ENT pathologies are viral, could be explained by the fact that the majority of cases received already showed signs of bacterial superinfection. Being in a tropical zone, bacterial superinfection is found in many cases and the difficulty of access to paraclinical examinations, especially the antibiogram also justifies this antibiotic probabilistic in our environment. As patients consult for persistent symptoms, they require good symptomatic management outside of the cause, hence the high frequency of anti-inflammatory drugs. The low rate of surgery is a function of the low rate of diagnosis requiring surgical treatment, the difficulties of paraclinical confirmation of certain diagnoses, the insufficient technical platform and the difficulties of access to health care.

The treatment was ambulatory in $98.70 \%$ of the cases while $1.30 \%$ of the cases were hospitalized. Other authors have also found a predominance of outpatient treatment [3] [4] These figures can be explained by the fact that the ORL service organizes more outpatient consultations and hospitalises very few patients, particularly those who have undergone surgery and requiring parenteral treatment.

As for post-treatment outcome, healing was reported in $44.34 \%$ of cases; $55.66 \%$ of cases were lost of view and no deaths were recorded in our series. This 
high rate of patients lost of view may be due to the fact that patients generally do not prefer to see the doctor for a post-treatment check, assuming to be cured since no longer having any symptoms.

\subsection{Limitations of the Study}

It should be noted that this study has encountered a few limitations. In fact, the collection of the data was carried out retrospectively, based on the archived files and registers of the patients. Therefore, we must note a lack of certain parameters that are not always included in the files. On the other hand, it is possible that there is a relative underestimation of the cases, some patients being treated directly in pediatrics. Nevertheless, despite all these limitations, we believe that the overall objectives of this study have been achieved.

\section{Conclusion}

This study showed that ENT diseases in children are common in routine consultation in the context of this hospital study. The diagnoses are generally simple, dominated by infections, and the management is more consistent when the patients resort directly to the competences of the assigned ENT department. Since then, the evolution is often favorable but the high rate of patients lost of view remains a fault which makes difficult the estimation of the success rate of treatment initiated.

\section{What Is Already Know on This Topic}

- Children are vulnerable and more exposed to ENT pathologies and complications.

- Specialized ENT consultations are not very accessible in countries with limited resources.

\section{What This Study Adds}

- This study provides a clarified breakdown of the most common causes of ENT diseases in children in a hospital in the context of a country with limited resources (DR Congo).

- It shows that rational and specific management could improve the quality of diagnosis and reduce the risk of complications.

\section{Authors' Contributions}

- Yowa Muya Sandra designed the first draft of the study and conducted data collection.

- Yowa Muya Sandra and Kanteng Gray analyzed the data and wrote the first manuscript.

- Nyembo Luty Albert, Mutombo Augustin and Luboya Oscar participated in the review of the literature and the various corrections. 


\section{Conflicts of Interest}

The authors declare no conflicts of interest regarding the publication of this paper.

\section{References}

[1] Attifi, H., Hmidi, M., Boukhari, A., Touihem, N., Kettani, M., Zalagh, M., et al. (2014) Expérience oto-rhino-laryngologique de l'hôpital marocain de campagne en Guinée Conakry. Pan African Medical Journal, 19, 40. https://doi.org/10.11604/pamj.2014.19.40.4908

[2] Fasunla, A.J., Samdi, M. and Nwaorgu, O.G. (2013) An Audit of Ear, Nose and Throat Diseases in a Tertiary Health Institution in South-Western Nigeria. Pan African Medical Journal, 14, 1. https://doi.org/10.11604/pamj.2013.14.1.1092

[3] Donkeng, M.J., Djomou, F., Nzogang, M.K. and Njock, R.L. (2016) Les urgences ORL à l'Hôpital Général de Douala. Human Health and Disease, 17, 41-46.

[4] Badou-N'guessan, K.E., Tanon-Anoh, M.J., N'guessan, N.S., Yoda, M., Buraima, F. and Kouassi, B. (2017) Urgences ORL de l'enfant au CHU de Yopougon (Cote d'Ivoire). Medecine d' Afrique Noire, 64, 91-98.

[5] Ramarozatovo, N.P., Razafindrakoto, R.M., Rakotoarisoa, A.H.N., et al. (2010) Épidémiologie des urgences pédiatriques en ORL à Antananarivo résultats préliminaires. Revue d'Anesthésie-Réanimation et de Médecined'Urgence, 2, 1-4.

[6] Choi, K.J., Kahmke, R.R., Crowson, M.G., Puscas, L., Scher, R.L. and Cohen, S.M. (2017) Trends in Otolaryngology Consultation Patterns at an Academic Quaternary Care Center. JAMA Otolaryngology_Head \& Neck Surgery, 143, 472. https://doi.org/10.1001/jamaoto.2016.4056

[7] Seymour, M.C., Pardo, J.J. and Bahamonde, S.H. (2011) Patología otorrinolaringológica ambulatoria en el Hospital Clínico de la Universidad de Chile durante el año 2008: Reporte de 9.157 pacientes. Revista de Otorrinolaringología y Cirugía de Cabeza y Cuello, 71, 237-240. https://doi.org/10.4067/S0718-48162011000300008

[8] Ministère du Plan, République Démocratique du Congo (2005) Monographie de la Province du Katanga. 147.

[9] Kitcher, E., Jangu, A. and Baidoo, K. (2007) Emergency Ear, Nose and Throat Admissions at the Korle-Bu Teaching Hospital. Ghana Medical Journal, 41, 9-11.

[10] Adedeji, T.O., Sogebi, O.A. and Tobih, J.E. (2015) Pattern of Otorhinolaryngological Admissions via Emergency Unit in a Suburban Tertiary Center. International Journal of Biomedical Science: IJBS, 11, 146-151.

[11] Diallo, A.O., Kolié, D., Itiéré Odzili, F.A., Keita, A., Delamou, A., Diallo, M.T., et al. (2017) Aspects Cliniques des Urgences ORL Infantiles à l'Hôpital National Ignace Deen (CHU de Conakry). Health Sciences, 18, 76-79.

[12] Sereme, M., Tarnagda, S., Guiguimde, P., Chantal, Y.M., Ouedraogo, B., Céline, B., et al. (2016) Les urgences infectieuses ORL. Pan African Medical Journal, 25, 27. https://doi.org/10.11604/pamj.2016.25.27.9830

[13] Dervaux, J. (2014) Infections ORL de l'enfant-Solutions naturelles. Ed. Dangles, 80.

[14] Furtado, P.L., Nakanishi, M., Rezende, G.L., Granjeiro, R.C. and Oliveira, T.S. (2011) Clinic-Epidemiological Analysis of an Otorhinolaryngology Emergency Unit Care in a Tertiary Hospital. Brazilian Journal of Otorhinolaryngology, 4, 426-231. 
https://doi.org/10.1590/S1808-86942011000400004

[15] de Andrade, J.S.C., de Albuquerque, A.M.S., Matos, R.C., Godofredo, V.R. and de Oliveira Penido, N. (2013) Profile of Otorhinolaryngology Emergency Unit Care in a High Complexity Public Hospital. Brazilian Journal of Otorhinolaryngology, 79, 312-316. https://doi.org/10.5935/1808-8694.20130056

[16] Sahin, S., Bayindir, T., Cingi, C., Erdogmus, N., Gurbuz, M.K., Cakli, H., et al. (2013) Epidemiologic Variation in Pediatric Ear, Nose, and Throat Diseases: Pediatric Emergency Admissions in Two Different Regions of Turkey. Journal of Pediatric Sciences, 5, e187.

[17] Kishve, S.P., Kumar, N., Kishve, P.S., Aarif, A.M.M. and Kalakoti, P. (2010) Ear, Nose and Throat Disorders in Paediatric Patients at a Rural Hospital in India. Australasian Medical Journal, 3, 786-790. https://doi.org/10.4066/AMJ.2101.494

[18] Adhikari, P., Kharel, B., Ma, J., Baral, D.R., Pandey, T., Rijal, R., et al. (2008) Pattern of Otological Diseases in School Going Children of Kathmandu Valley. International Archives of Otorhinolaryngology, 12, 502-505.

[19] Lalwani, A.K. (2008) Current Diagnosis \& Treatment in Otolaryngology: Head \& Neck Surgery. McGraw-Hill, New York. 